Article

\title{
Spatial Diffusion of Taiwanese Enterprises in Mainland China under the Vision of Rural Industrial Vitalization
}

\author{
Mingshui Lin ${ }^{1,2}{ }^{\oplus}$, Juan Lin ${ }^{1, *}$, Caibin Lin $^{3}$, An Zhang ${ }^{2}$ and Kaiyong Wang ${ }^{2, *}$ \\ 1 College of Tourism, Fujian Normal University, Fuzhou 350117, China; linms@fjnu.edu.cn \\ 2 Institute of Geographic Sciences and Natural Resources Research, Chinese Academy of Sciences, \\ Beijing 100101, China; zhangan@igsnrr.ac.cn \\ 3 College of Economics, Fujian Normal University, Fuzhou 350117, China; lincb@fjnu.edu.cn \\ * Correspondence: fqlinjuan@foxmail.com (J.L.); wangky@igsnrr.ac.cn (K.W.); Tel.: +86-18065162591 (K.W.)
}

Received: 17 September 2018; Accepted: 11 October 2018; Published: 14 October 2018

\begin{abstract}
The Taiwanese, who have accumulated rich experience from the strategy, have greatly promoted the development of the rural economy in mainland China through the establishment of rural Taiwanese enterprises. In the process of the strategy of rural revitalization, it is important to draw on the experience from Taiwan, and to acknowledge the leading role of Taiwanese entrepreneurs. In this study, we considered 941 rural Taiwanese enterprises that were registered in townships and villages in mainland China. Based on the cultural diffusion model, spatial analysis of GIS, and statistical methods, this study analyzed the spatial pattern and evolution of rural Taiwanese enterprises, and predicted the spatial diffusion pattern as well. The study found the following: (1) The reform and opening-up policy leads to the core position of Dongguan and Kunshan, and continues to consolidate the dual-core pattern with a noticeable combined effect. (2) Rural Taiwanese enterprises are mainly engaged in the secondary industry, with characteristics of small-scale and strong independence. They tend to be located in secondary cities in developed regions, in order to reduce costs and obtain maximum profits. (3) They display a V-shaped pattern covering the Eastern coastal line and Hunan-Sichuan line, with Guangdong as the node. (4) It is predicted that, in the next decade, the growth of the enterprises will slow down and their spatial diffusion pattern will be more conspicuous. While the spatial diffusion of Taiwanese enterprises slows down, more domestic investment may lead to industry vitalization in rural China.
\end{abstract}

Keywords: rural Taiwanese enterprises; rural industrial vitalization; spatial diffusion; China

\section{Introduction}

Rural Vitalization is a global issue [1]. In the context of globalization and urbanization, developed countries in both North America and Europe [2,3], and developing countries in Asia and Africa $[4,5]$, are exploring policies and measures to coordinate urban-rural integration and promote rural revitalization according to their national conditions. Rural revitalization is a process of sustained development for industry-fed agriculture and urban-fed rural areas [6,7]. Industrialized countries and regions have achieved rich experience in coordinating the relationship between urban and rural areas [8]. Rapid industrialization and urbanization bring "urban diseases" to European and American countries, such as high population density, traffic jams, and the heat island effect in urban development; then, they started the strategy of rural revitalization, such as the development of new towns in the United States in the 1960s, the construction of rural central villages in the United Kingdom, and the "rural revitalization plan" in France [3,6,8]. While Japan and South Korea, as the representatives of the post-industrialized countries in East Asia, drew lessons from them and launched rural revitalization 
later [9]. In the 1970s, Korea launched the "new rural movement", and Japan started the demonstration project of comprehensive rural construction [1]. These countries took serval actions to promote rural area, including the construction of rural community infrastructure, activating the use of rural land resources and assets, improving rural production and living conditions, and attracting people to return home, thus stimulating the vitality of rural development [10].

The government of China implemented the "rural vitalization strategy" at the 19th Communist Party of China (CPC) National Congress, aiming to address the imbalanced and insufficient development caused by the traditional dual structure of urban and rural areas under the background of rapidly developed new-type urbanization [11]. It has become the priority of work and a core task of government at various levels [12]. In fact, Taiwan drew lessons from Japan and South Korea [13] and started to implement the rural vitalization strategy $[14,15]$ back in the 1980s, accumulating valuable experience in delicate agriculture [16], new-type professional farmers [17], rural eco-environmental issues [18], factor mobility between urban and rural areas [19], and rural governance systems [20]. With the reform and opening up policy being carried out, more Taiwanese compatriots got a proper environment for financing innovation and entrepreneurship in mainland China, such as township enterprises [21,22], Taiwanese farmer pioneer parks [23], and leisure farms [24]. Greater Straits of connectivity help to gather a large number of Taiwanese talents, who engaged in Taiwanese investment parks, Taiwanese farmer pioneer parks, leisure farms, and traditional homestay hotels. Various business models substantially boosted the local rural industrial vitalization. Both sides of the Taiwanese Strait share the same ancestry. The experience and achievements of Rural Revitalization in Taiwan have crossed the Taiwanese Strait and have spread in the mainland. We have summarized Taiwan's experience in rural vitalization, putting into play the leading and demonstrating role of Taiwanese compatriots in rural industrial vitalization [25], aiming to provide some valuable guides for mainland rural vitalization in theory and practice.

Rural vitalization is a systematic project [26] that covers various aspects, such as society, economy, culture, and ecology [27]. (1) Regarding the content of rural vitalization, domestic and overseas research shows that the primary task of rural vitalization is to promote rural industrial vitalization, that is, establishing a rural industrial system that focuses on modern agriculture, and improves the integration of rural primary, secondary, and tertiary industries [1]. Liu summarizes rural vitalization into "five constructions", among which industrial prosperity is an important foundation of economic construction. He also emphasizes the importance of resource integration, industrial cultivation, economic transformation, and income growth [11]. However, the study fails to pay sufficient attention to Chinese traditional rural governance culture [28,29]. (2) In terms of a specific path, the successful implementation of various "new village movement" strategies in Europe, America, Japan, and South Korea lies in the practice of the top-down or bottom-up approach. At the early stage, the government is the main force promoting rural development; during the growth period, civilians independently spare no efforts to advance rural industrial development, environmental improvement, and cultural construction; at the mature stage, civilians drive community civilization construction and economic development entirely independently [30-32]. In China, rural vitalization at the early stage is predominated and promoted by the government [33]. Such a top-down mode is unitary in form, prone to excessive bureaucratization and formalization in the process of implementation, and is difficult to sustain. (3) In terms of participators, many participators are involved in rural vitalization, not only the local stakeholders [34], such as the government, villagers, new village elites, enterprises, and technicians, but also the incoming participating stakeholders such as enterprises, technicians, public welfare organizations, and volunteers. On such a basis, an industrial development system based on rural land, tied by talent and technology, and driven by capital is shaped [35]. Besides, at different vitalization stages in different countries and regions, the participators and the role they play may differ [36,37]. (4) For spatial diffusion, the strategy of rural revitalization was put forward and transitioned from Europe and America to Asia. In this new era, with the gradual completion of industrialization and urbanization in the vast areas of the mainland, the experience of 
rural revitalization in the developed countries and regions of Europe, America, and East Asia is bound to be further widespread and disseminated in the mainland, and will be gradually internalized and absorbed into the policies and measures of rural revitalization with mainland characteristics [38].

Rural industrial vitalization is the core and foundation of rural vitalization, and is also a popular yet difficult issue in the domestic and foreign study on rural vitalization [32,39]. At present, China has made significant research achievements in rural vitalization, but has neglected that, to a great extent, special participators such as new village elites, Taiwanese compatriots, and overseas Chinese citizens, can play an important role in the rural industrial vitalization [34], especially Taiwanese compatriots who have experience of Taiwanese rural vitalization, and have engaged themselves in rural industrial vitalization in Fujian and other areas in mainland China for over 20 years, accumulating rich and valuable experience. Despite the availability of some studies on spatial diffusion and the devolvement of Taiwanese enterprises in mainland China, they seldom focus on rural industrial vitalization. This perspective not only reflects the general features of the spatial layout of Taiwanese enterprises in mainland China, but also highlights the particularity based on rural geographical location. Therefore, it is necessary to review and summarize the general features of the Taiwanese compatriots participating in rural industrial vitalization in mainland China, and to further clarify the spatial diffusion path of Taiwanese enterprises in rural areas. Thus, we can help to improve the theoretical system on the rural industrial structure and offer reference for the implementation of rural industrial vitalization in mainland China.

\section{Data and Methods}

\subsection{Data Collection}

The Provisions of the State Council on Encouraging Investment by Taiwanese Compatriots, promulgated in 1988, encourages Taiwanese companies, enterprises, and individuals to invest in industry, agriculture, services, and other industries, in line with the direction of the social and economic development direction in mainland China in seven forms, including setting up enterprises entirely invested by Taiwan, setting up joint ventures and cooperative enterprises, conducting compensation trade, processing and assembling and cooperative production, purchasing stocks and bonds of enterprises, purchasing housing, and legally acquiring land use right, as well as development, operation, and other investment forms permitted by the laws and regulations. Among the seven forms, setting up sole proprietorship enterprises and joint ventures by Taiwanese compatriots are the most popular. The statistics across the Straits are available and reliable. The study takes the sole proprietorship Taiwanese enterprises and joint ventures as the major source of data for the engagement of Taiwanese compatriots in rural industrial vitalization.

The data in the study is derived from the Approved Investment Statistics of Taiwanese Investment Commission, a branch of the Ministry of Economic affairs. We collected the investment data in mainland China by listed Taiwanese enterprises and over-the-counter (OTC) Taiwanese enterprises, including the name, place of registration, time of registration, and code of getting listed for the OTC Taiwanese enterprises, and name of investment enterprises, registration place of investment enterprises, registration time of investment enterprises, and contact information of the investment enterprises. The listed and OTC Taiwanese enterprises are corporations whose stocks are publically traded at security exchanges with the approval of Taiwanese securities authorities, and the capital threshold is 600 million New Taiwan Dollar(TWD) for the listed enterprises and 50 million TWD for the OTC enterprises. They are both strong in credit and strength, large in size and high in level, and are fully capable of spatial diffusion. From 1997 to 2017, a total of 1540 listed (OTC) Taiwanese enterprises set up 4857 enterprises in mainland China, covering 18 industries in 29 provinces, autonomous regions, and municipalities. The wide and profound influence of their spatial diffusion in mainland China is representative across China and even the world, and thus is of great value for study. We collected 941 enterprises from these, which are registered in the towns and villages of rural areas. These data 
will greatly show Taiwanese compatriots participating in rural mainland vitalization (hereinafter, "rural Taiwanese enterprises"). Although these rural Taiwanese enterprises account for an estimated $5 \%$ of the total enterprises, they involve in 16 industries and cover 23 provinces, with an average registered capital of about 14 million U.S. dollars, and an average employment scale of 150-200 people. Therefore, these samples have good representativeness, which provides reliable data for our research.

\subsection{Methodology}

\subsubsection{GIS Spatial Analysis}

We use ArcGIS 10.3 (ESRI, Redlands, America) to build a database for the 941 rural Taiwanese enterprises, including information such as the company code, industry, region, establishment time, type of enterprise, and state of existence. We also analyze features of the spatial distribution of rural Taiwanese enterprises. We adopted the kernel density analysis to calculate their density, and used the geo-statistical analysis to predict the tendency of spatial diffusion.

\subsubsection{Spatial Diffusion Model}

The cultural diffusion model describes and explains the law and process of certain cultures spreading from the diffusion source outwards, and can be expressed with a basic diffusion model equation [38,40]. This model can be applied to economics activity diffusion and technology diffusion [8]. We assumed that, at any time point, the diffusion rate of rural Taiwanese enterprises is a function of the difference between the number of enterprises that could possibly be set up at the time point and the number of enterprises that are already established at the time point $([\bar{N}-N(t)])$. The spatial diffusion model of rural Taiwanese enterprises is illustrated with Formula (1).

$$
\frac{d N(t)}{d t}=g(t)[\bar{N}-N(t)]
$$

In Formula (1), $N(t)$ represents the number of rural Taiwanese enterprises accumulated at the time point $t$, and $\bar{N}$ means the potential number of the enterprises at the time point $t ; \frac{d N(t)}{d t}$ indicates the diffusion rate at the time point $t$, and $g(t)$ shows the diffusion coefficient.

Formula (1) shows a deterministic rate equation, where the form of relation and nature between the diffusion rate and the number of enterprises that could potentially be set up, $[\bar{N}-N(t)]$, are represented or controlled by the diffusion coefficient, $g(t)$. The value of $g(t)$ is determined by the features of the diffusion process, including the culture sharing of rural Taiwanese enterprises, the diffusion relationship, diffusion medium, and way of diffusion.

According to previous research results [41], the spatial diffusion of Taiwanese enterprises in mainland China is influenced by both internal factors and external factors. The former refers to cost, need for expanded operation and management, and so on, while the latter includes TWD depreciation, reform and opening up in mainland China, and so on. Therefore, the diffusion model with mixed factors should be adopted, as shown in Formula (2).

$$
N(t)=\frac{\bar{N}-\frac{\alpha\left(\bar{N}-N_{0}\right)}{\left(\alpha+b N_{0}\right)} e^{\left[-(\alpha+b \bar{N})\left(t-t_{0}\right)\right]}}{1+\frac{b\left(\bar{N}-N_{0}\right)}{\left(\alpha+b N_{0}\right)} e^{\left[-(\alpha+b \bar{N})\left(t-t_{0}\right)\right]}}
$$

$\bar{N}$ can be regarded as the asymptote of the spatial diffusion curve.

2.2.3. Spatial Diffusion Index for Rural Taiwanese Enterprises

\subsubsection{Create Evaluation System}

This study creates a spatial diffusion system of rural Taiwanese enterprises in order to reflect the spatial diffusion of the Taiwanese compatriots engaging in rural industrial vitalization. Five indices 
namely, the type of enterprise, registered capital, establishment time, registered status, and terms of operation, are used as the main evaluation indices for the spatial diffusion index (Table 1). We argue that these five indices have a significant relationship with the spatial diffusion of rural Taiwanese enterprises, with the following exceptions: (a) Joint venture rural Taiwanese enterprises may be more likely to diffuse than sole proprietorship enterprises. Joint venture Taiwanese enterprises have more frequent communications with local villages, which is conducive to their spatial diffusion. (b) A higher registered capital reflects the stronger strength of the enterprises and is more helpful for the spatial diffusion. (c) An earlier establishment of the enterprises reflects a deeper integration with local areas and is better for the spatial diffusion. (d) Enterprises that currently exist and are in business are considered business activities, and this works to the advantage of spatial diffusion. (e) A longer duration means that the enterprises have more opportunities and a higher ability to diffuse.

Table 1. Index description and data source.

\begin{tabular}{|c|c|c|c|}
\hline Index & Index Description & Expectation & Data Source \\
\hline Type of enterprise & $\begin{array}{l}\text { Including joint venture (JV) and sole proprietorship } \\
\text { enterprises, reflecting ways of diffusion. }\end{array}$ & $\mathrm{JV}+$ & National Enterprise \\
\hline Registered capital & $\begin{array}{l}\text { Total capital registered with administrative authority when } \\
\text { setting up a business entity, reflecting diffusion strength. }\end{array}$ & + & $\begin{array}{l}\text { Credit Information } \\
\text { Publicity System } \\
\text { http: / / www.gsxt.gov. }\end{array}$ \\
\hline Establishment time & $\begin{array}{l}\text { Date approved by the industry and commerce authority } \\
\text { when handling an enterprise establishment for the first time, } \\
\text { reflecting time of diffusion. }\end{array}$ & - & cn/index.html \\
\hline Registered status & $\begin{array}{l}\text { Including existing, in business, revoked, cancelled, } \\
\text { immigrated, emigrated, suspended, and } \\
\text { liquidated-reflecting the current status of diffusion. }\end{array}$ & $\begin{array}{l}\text { Existing }+ \text { and in } \\
\text { business }+\end{array}$ & \\
\hline Term of operation & $\begin{array}{l}\text { Time duration of an enterprise from establishment until now } \\
\text { or until cancellation. }\end{array}$ & + & \\
\hline
\end{tabular}

Note: + is a positive effect; - is a negative effect.

\subsubsection{Standardization of the Evaluation Indices}

The evaluation indices are standardized so as to address the discrepancy between the indices' dimensions and their physical significance, as well as the incomparability of parameters. The range method is used to assign value to the correlation between the evaluation indices and spatial diffusion. The greater the positive correlation, the stronger the diffusion ability; the greater the negative correlation, the lower the diffusion ability.

The graded value assignment method is used to evaluate the type of enterprise, registered capital, date of establishment, terms of operation, and registered status, and the natural breaks class is adopted to normalize the registered capital and date of establishment (Table 2). The terms of operation are subject to extremum normalization and the type of enterprise and registered status are subject to a direct graded value assignment, according to expertise and actual diffusion laws.

Table 2. Standardized value assignment.

\begin{tabular}{cccccc}
\hline \multirow{2}{*}{ Index } & \multicolumn{5}{c}{ Standardized Value Assignment } \\
\cline { 2 - 6 } & $\mathbf{2}$ & $\mathbf{4}$ & $\mathbf{6}$ & $\mathbf{8}$ & $\mathbf{1 0}$ \\
\hline \multirow{2}{*}{ Type of Enterprise } & \multicolumn{5}{c}{ Sole } \\
& \multicolumn{5}{c}{ Proprietorship } \\
\hline Registered capital (USD 10,000) & $<933$ & $933 \sim 2800$ & $2800 \sim 7800$ & $7800 \sim 13,400$ & Joint Venture \\
Establishment time (Year) & $2013 \sim 2017$ & $2009 \sim 2012$ & $2004 \sim 2008$ & $2000 \sim 2003$ & $1997 \sim 1999$ \\
Term of operation (Year) & $1 \sim 2$ & $3 \sim 4$ & $5 \sim 600$ \\
Registered status & & & Revoked, cancelled & $7 \sim 8$ & Existing, in business \\
\hline
\end{tabular}

\subsubsection{Identification of the Index Weight}

The analytic hierarchy process (AHP) is adopted to analyze the weight of the five indices. We invited 15 experts in geography, economics, and management science to compare their relative importance. Five geography experts, two economics experts, and two management science experts 
came from universities and research institutions, and another three economics experts and three management science experts came from economics and management sections. These experts assigned values from one to nine, after comparing the importance of each index. We ran the Yaahp v10 software (Meta decision software technology Co., Ltd., Shanxi, China) to statistically analyze the weight of these values, and the results are shown in Table 3.

Table 3. Weight of evaluation index.

\begin{tabular}{ccc}
\hline Index & Weight & Consistency Test of Judgment Matrix \\
\hline Type of enterprise & 0.28 & \\
Registered capital & 0.40 & $0.03<0.10$ \\
Establishment time & 0.05 & \\
Term of operation & 0.10 & \\
Registered status & 0.17 & \\
\hline
\end{tabular}

\subsubsection{Spatial Diffusion Index}

The spatial diffusion index (SDI) of rural Taiwanese enterprises is built so as to evaluate their capability of spatial diffusion. Based on the spatial diffusion evaluation index system, the SDI is further calculated by considering the impact of all of the indices on spatial diffusion of the enterprises, as follows:

$$
S D I_{n}=0.28 X_{n}+0.40 Y_{n}+0.05 Z_{n}+0.10 S_{\mathrm{n}}+0.17 T_{n}
$$

In Formula (3), $S D I_{n}$ represents the spatial diffusion index of the $n$th rural enterprise, while $X_{n}, Y_{n}$, $Z_{n}, S_{n}$, and $T_{n}$ refer to the index value of the type of enterprise, registered capital, date of establishment, term of operation, and registered status of the $n$th rural enterprise.

\section{Results and Analysis}

\subsection{Spatial Pattern of Rural Taiwanese Enterprises}

\subsubsection{Pattern of Temporal and Spatial Distribution}

Temporally speaking, the number of rural Taiwanese enterprises rapidly grew in the early years, slowed down after reaching the peak of growth in the middle years, and maintained a trend of slow growth at the later stage, as shown in Figure 1. To be specific, in 1997-1999, there were only 31 rural Taiwanese enterprises, with an average of 10 set up annually. In 2000-2009, 648 were newly established, with an average annual increase of 65. In 2010-2017, 262 were set up, with an annual average increase of 26 . The growth was greatly affected by the national policies and international economic situation. Especially in the 21st century, the ease of the cross-Strait relations considerably promoted the growth of the enterprises. However, under the impact of the 2008 global financial crisis as well as the global economic slowdown of recent years, the growth of the enterprises has correspondingly fluctuated to some extent.

Spatially speaking (Figure 2), rural Taiwanese enterprises are distributed to the east of $\mathrm{Hu}$ Line, with $94.90 \%$ of them concentrated in the Eastern region, with $2 \%$ distributed in the Central region and Western region, respectively. Only two enterprises, the smallest share, are located in Northeast China. In 1997-1999, the enterprises were mainly distributed in Dongguan City, Guangdong Province, and Kunshan City, Jiangsu Province, because of regional favorable policies. Since the reform and opening up, the Pearl River Delta area implemented the "One Step Ahead" strategy and became the favorable destination for Taiwanese investment. Compared with Taiwan, Dongguan boasted the absolute edges in labor cost, raw material cost, and, together with its preferential policies in land, rapidly attracted Taiwanese enterprises. The development of Kunshan was attributable to the reform and opening up, as well as the investment wave in the Pudong New Area, Shanghai. As the global capital flooded into Shanghai, the Taiwanese investment on a smaller scale turned to Kunshan, which is 
close to Shanghai, and triggered a series of domino effects. In 2000-2009, the newly established rural Taiwanese enterprises expanded outwards around the center of Dongguan and Kunshan, and shaped a noticeable "core periphery" structure. At this stage, preferential policies of government were further enhanced and, at the same time, the Taiwanese business culture started to be rooted in the two core areas, which further attracted more investment from Taiwan, forming the dual-core combined effect. Meanwhile, a large number of rural Taiwanese enterprises emerged in the Eastern coastal cities and some showed up in the Central and Western regions. In 2010-2017, newly set Taiwanese enterprises generally expanded towards Central and Eastern provinces rather than to Guangdong and Jiangsu. In the Central region, they were mainly distributed in Hunan, and the Western region they were mainly distributed in Sichuan and Guizhou. As labor cost, raw material cost, and land cost increased in the Eastern region, the Central and Western regions greeted new opportunities.

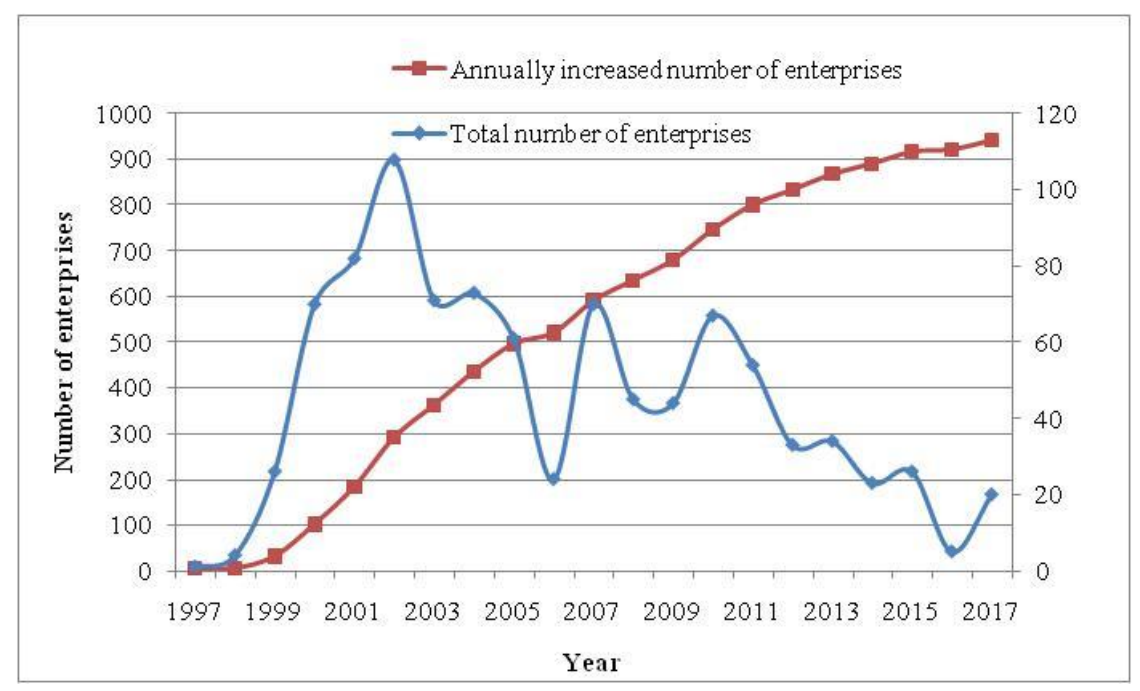

Figure 1. The quantity chart of rural Taiwanese enterprises between 1997-2017.

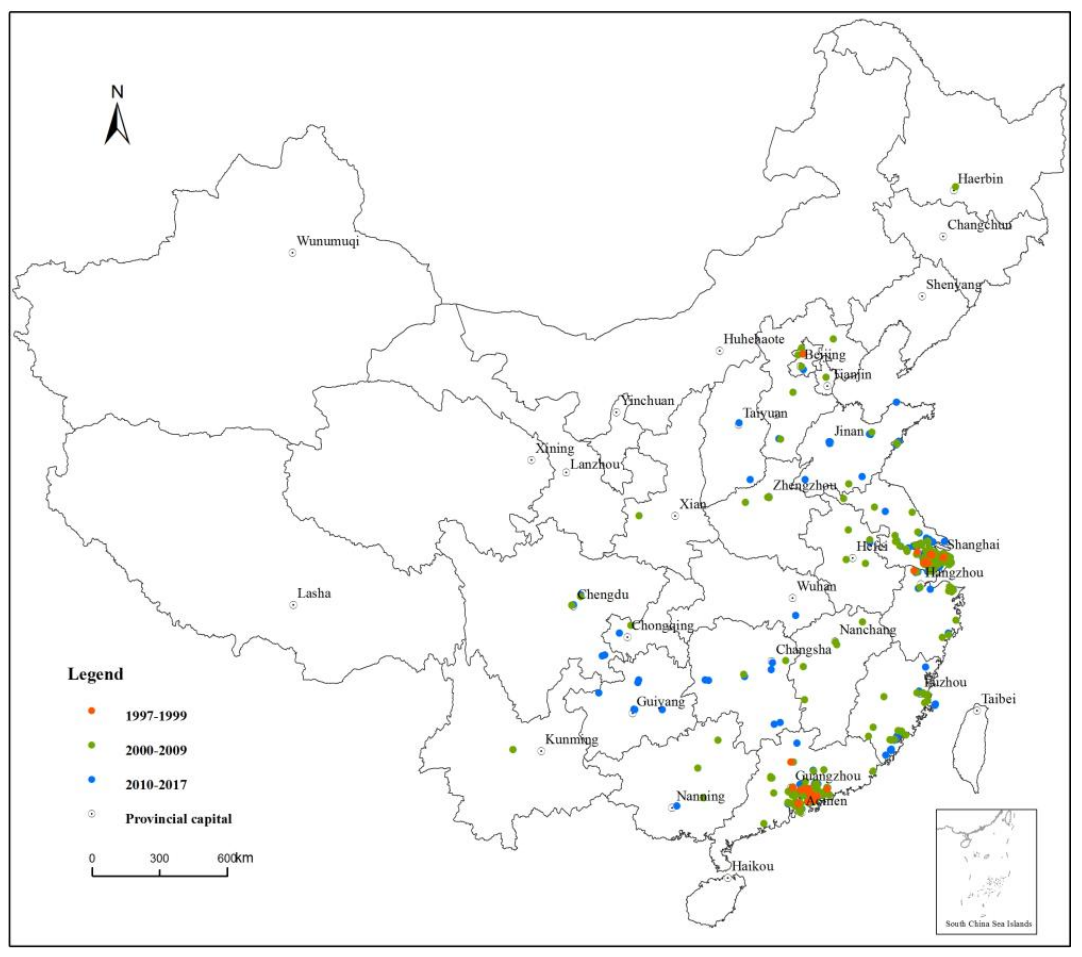

Figure 2. The spatial pattern of rural Taiwanese enterprises. 
In statistics, kernel density estimation (KDE) is a non-parametric way to estimate the probability density function of a random variable. It is widely used in spatial pattern analysis [42]. In order to further analyze the spatial agglomeration of rural Taiwanese enterprises, the study uses ArcGIS to draw a kernel density map of rural Taiwanese enterprises in 2017 (Figure 3). The result shows that the enterprises are concentrated in the Yangtze River Delta and Pearl River Delta area, forming intense clusters at these two points. Specifically, the density of the Pearl River Delta reaches the fifth grade and that of the Yangtze River Delta area reaches the third grade, lower than the former. No cluster of enterprises has been detected in other provinces or cities. This indicates that although the rural Taiwanese enterprises show a trend of diffusion in spatial distribution in mainland China, they exhibit the feature of path-dependence to a great extent. Besides the local preferential policies that advocate an early trial run first, rural Taiwanese enterprises are being locally embedded and are closely intertwined with local production networks and social network, both of which exert major influence over the dual-core pattern of Taiwanese enterprises in mainland China.

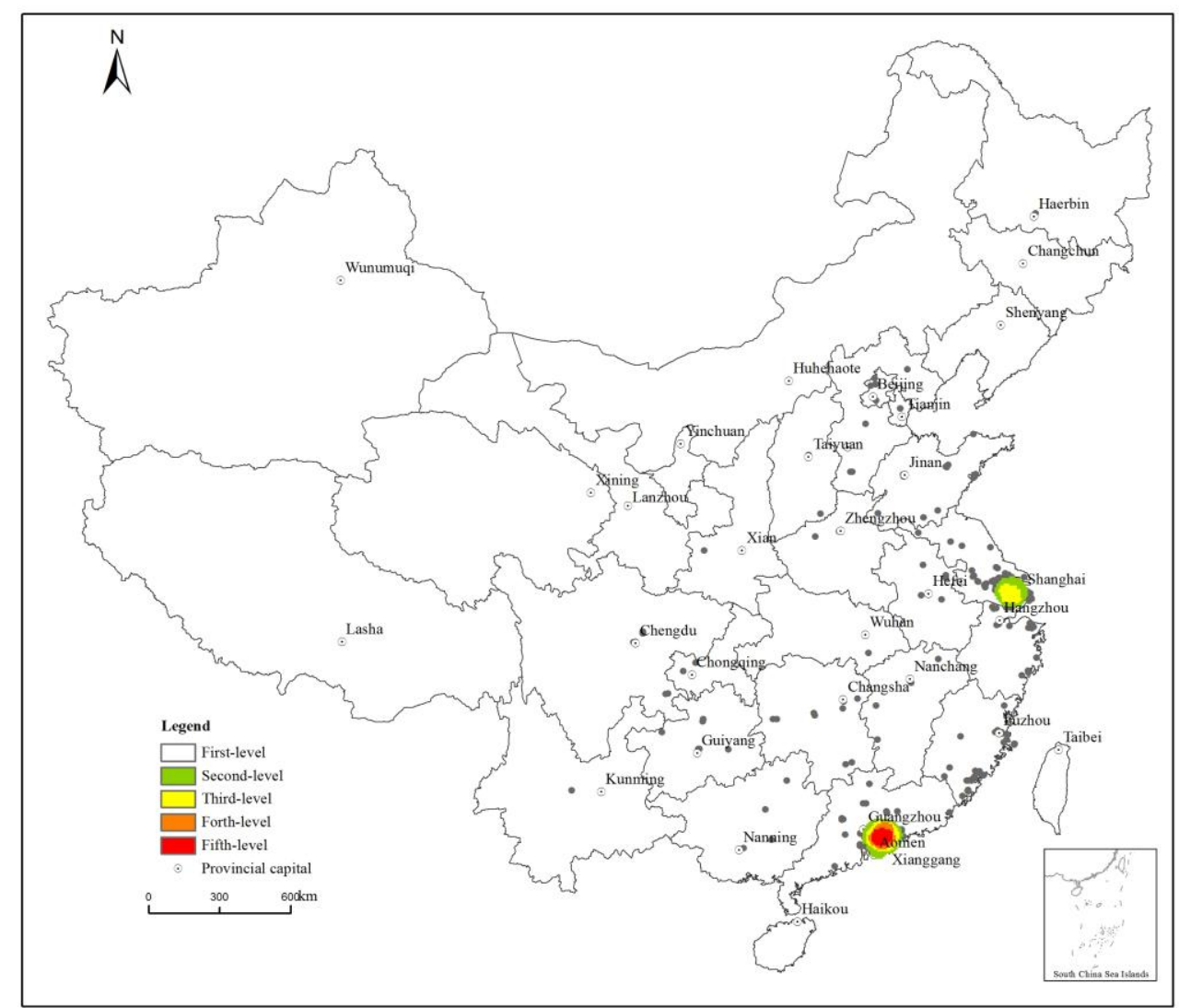

Figure 3. Point density analysis of rural Taiwanese enterprises.

\subsubsection{Spatial Pattern by Category}

\section{(1) By Industry}

According to the Industrial Classification for National Economic Activities (GB/T 4754-2017), rural Taiwanese enterprises are divided into three industries, as shown in Figure 4. Only seven are in the primary industry, accounting for $0.74 \%$, and are scattered in four provinces, namely Guangdong, Jiangsu, Yunnan, and Zhejiang; 763 fall in the secondary industry, accounting for $81.08 \%$, and are mainly distributed in the four provinces of Guangdong, Jiangsu, Shanghai, and Fujian; and 161 are in the tertiary industry, accounting for $18.18 \%$, and are spread in other Eastern provinces.

It can be seen that investment in processing and manufacturing is the primary channel for rural Taiwanese enterprises to realize rural industrial vitalization. Despite its low position in the production 
value chain, processing and manufacturing easily absorb the rural labor force and enjoy a large industrial size, which is still able to promote rural economic growth. The tertiary industry has a low penetration rate, mainly because the rural area is limited in talent, technology, capital, and location, which also restricts the transformation of the primary and secondary industry to the tertiary industry.

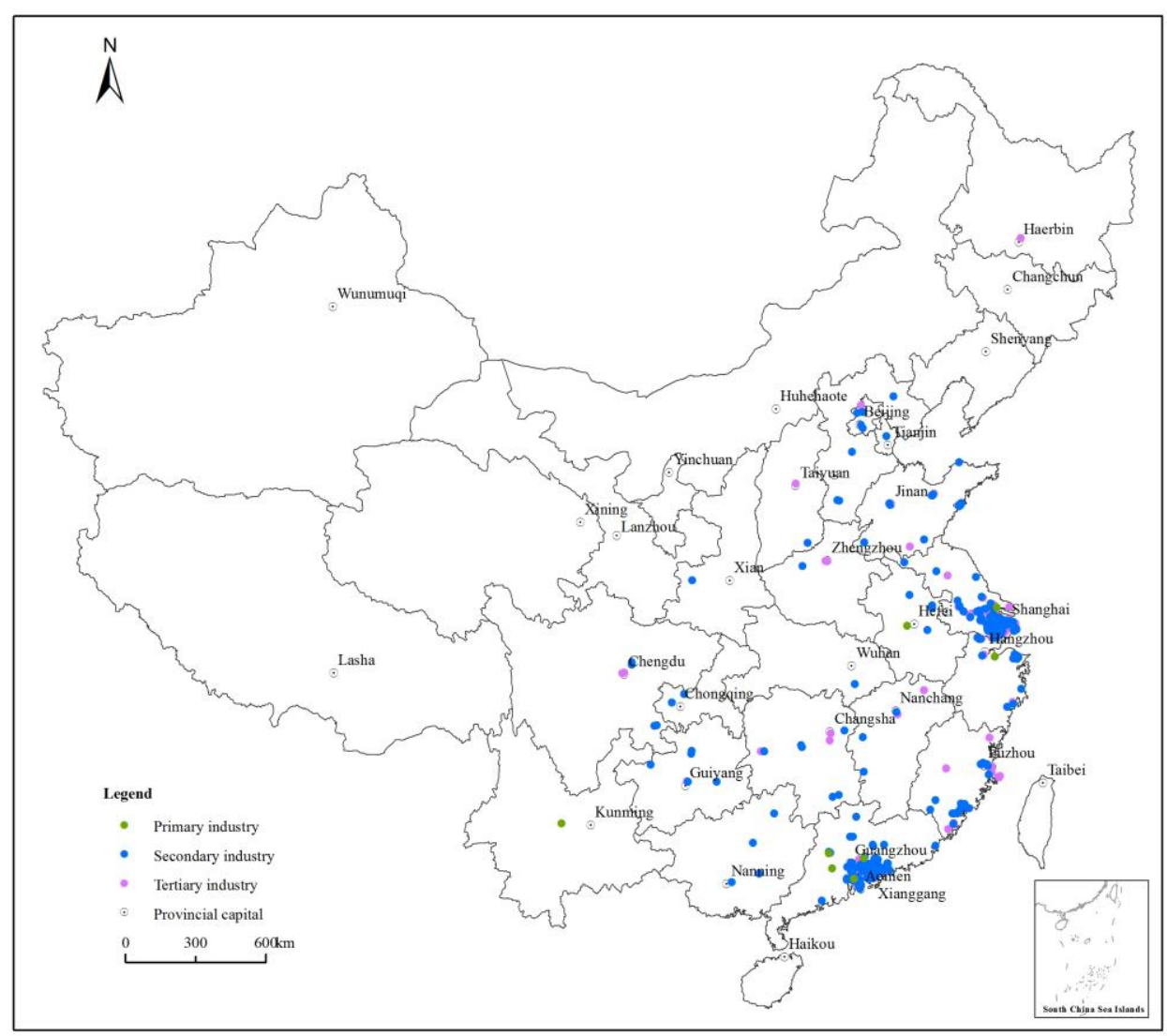

Figure 4. The spatial pattern of the industries belonging to rural Taiwanese enterprises.

(2) By Investment Size

The registered capital of rural Taiwanese enterprises is used to measure their size. The enterprises in 2017 are categorized into five grades with natural break classes, as shown in Figure 5. Spatially speaking, six of them fall in the fifth grade in the registered capital, with a total value of 1.9 billion USD. They are distributed in Kunshan in Jiangsu (quantity: two), Yingde in Guangdong, Jiaxing in Zhejiang, Jinan in Shandong, and Fuzhou in Fujian, and the industries they belong to are mainly mining (2), cement production, manufacturing, and electronic product production. The enterprise with the largest registered capital, of 500 million USD, is the Sunnsy Group in Gushan Town, Changqing District, Jinan City in Shandong. There are 31 enterprises that fall in the fourth grade in registered capital, with a total value of 3.7 billion USD, which are mainly distributed in Guangdong (16), Jiangsu (8), Fujian (3), Shanghai, Zhejiang, Sichuan, and Anhui. There are 82 that are at the third grade for registered capital, with a total value of 3.2 billion USD. There are 191 that are at the second grade for registered capital, with a total value of 3.1 billion USD. There are 631 that are at the first grade for registered capital, with a total value of 1.5 billion USD. 


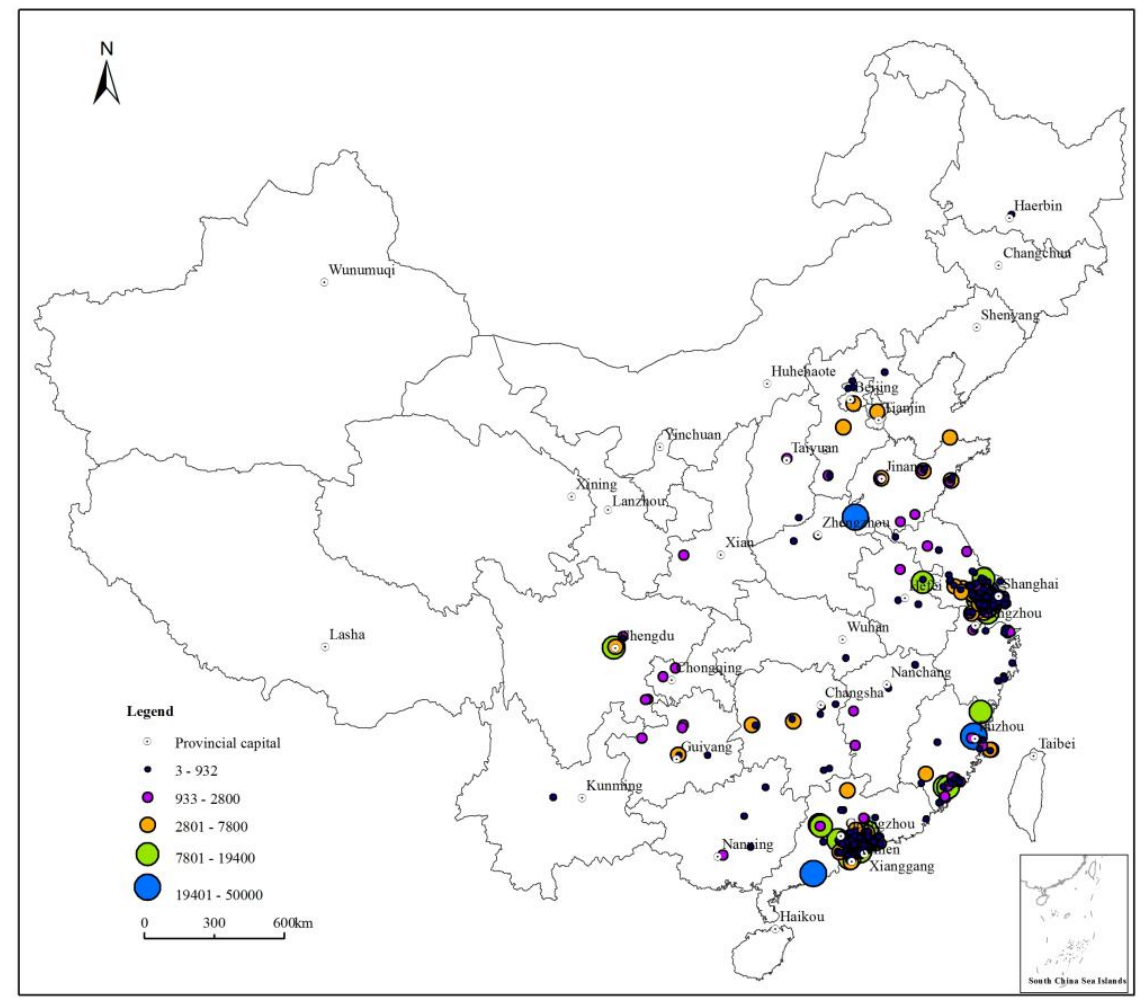

Figure 5. Registered capital distribution map of rural Taiwanese enterprises.

The share of rural enterprises at the first and second grade approaches $90 \%$, but their registered capital accounts for only $34.71 \%$ of the total, while the registered capital of the rural Taiwanese enterprises is averaged at 14.3 million USD. This indicates that the enterprises show the trend of polarization in size, which indirectly attests to the fact that, given their smaller investment size, rural Taiwanese enterprises tend to choose secondary cities surrounding first-tier cities and second-tier cities in pursuit of lower costs and maximized profit. Regarding the category of industry, the rural enterprises at all grades mainly fall within the secondary industry, with some in the tertiary industry, and an extremely small proportion in the primary industry.

(3) By Types of Enterprise

Rural Taiwanese enterprises are mainly sole proprietorships, as shown in Table 4 . There are 767 sole-invested enterprises, which account for $71.20 \%$, and their registered capital totals 9.2 billion USD, accounting for $68.51 \%$. There are 174 joint ventures, accounting for $28.80 \%$, and their total registered capital is 4.2 billion USD, accounting for $31.49 \%$ of the total.

Table 4. Investment type of rural Taiwanese enterprises.

\begin{tabular}{ccc}
\hline Region & Sole Proprietorship (Number/\%) & Joint Venture (Number/\%) \\
\hline Nationwide & $767(71.20 \%)$ & $174(31.49 \%)$ \\
Eastern region & $735(82.31 \%)$ & $158(17.69 \%)$ \\
Central region & $20(76.92 \%)$ & $6(23.08 \%)$ \\
Western region & $9(45 \%)$ & $11(55 \%)$ \\
Northeast region & $1(50 \%)$ & $1(50 \%)$ \\
Fujian Province & $16(48.48 \%)$ & $17(51.52 \%)$ \\
\hline
\end{tabular}

Regionally speaking(see Appendix A), out of the 893 enterprises in the Eastern region, the number of sole proprietorship enterprises accounts for $82.31 \%$, and their registered capital accounts for $68.95 \%$ of the total. In other provinces and cities in the Eastern region, besides Fujian, the number and 
total of registered capital of sole proprietorship enterprises both exceed the joint ventures. In Fujian, joint ventures not only outnumber sole proprietorship enterprises, but the total registered capital of the former is 3.87 times that of the latter. Among the 26 enterprises in the Central region, the number of sole proprietorship enterprises accounts for $76.92 \%$. and their total registered capital accounts for $72.41 \%$. In all of the provinces and cities in the region, sole proprietorship enterprises are predominating. Among the 20 enterprises in the Western region, the number of sole proprietorship enterprises accounts for $45 \%$, and their total registered capital accounts for $51.55 \%$. In the Northeast region, there is only one joint venture and one sole proprietorship of a rural Taiwanese enterprise.

Except for Fujian, the type of rural Taiwanese enterprises in other regions and even nationwide is quite consistent, that is, sole proprietorship enterprises show the overwhelming advantage. The result shows that Taiwanese enterprises are independent and exclusive to some extent when investing in mainland China. They have little cooperation with the areas being invested in. The exception of Fujian is mainly as a result of the special ties across the Strait in affinity, geography, region, business, and materials, which promotes the birth of joint ventures between the two sides and drives rural industrial vitalization.

\subsection{Process of Spatial Diffusion of Rural Taiwanese Enterprises}

\subsubsection{Features of Spatial Diffusion Index}

The spatial diffusion index grade of rural the Taiwanese enterprises shows the V-shaped spatial feature, as shown in Figure 6. The enterprises with a higher diffusion index are distributed in Guangdong, Jiangsu, Fujian, Zhejiang, and Shandong in the coast area, and the hinterland of Hunan and Sichuan, forming clusters with a high diffusion index in Guangdong and Jiangsu.

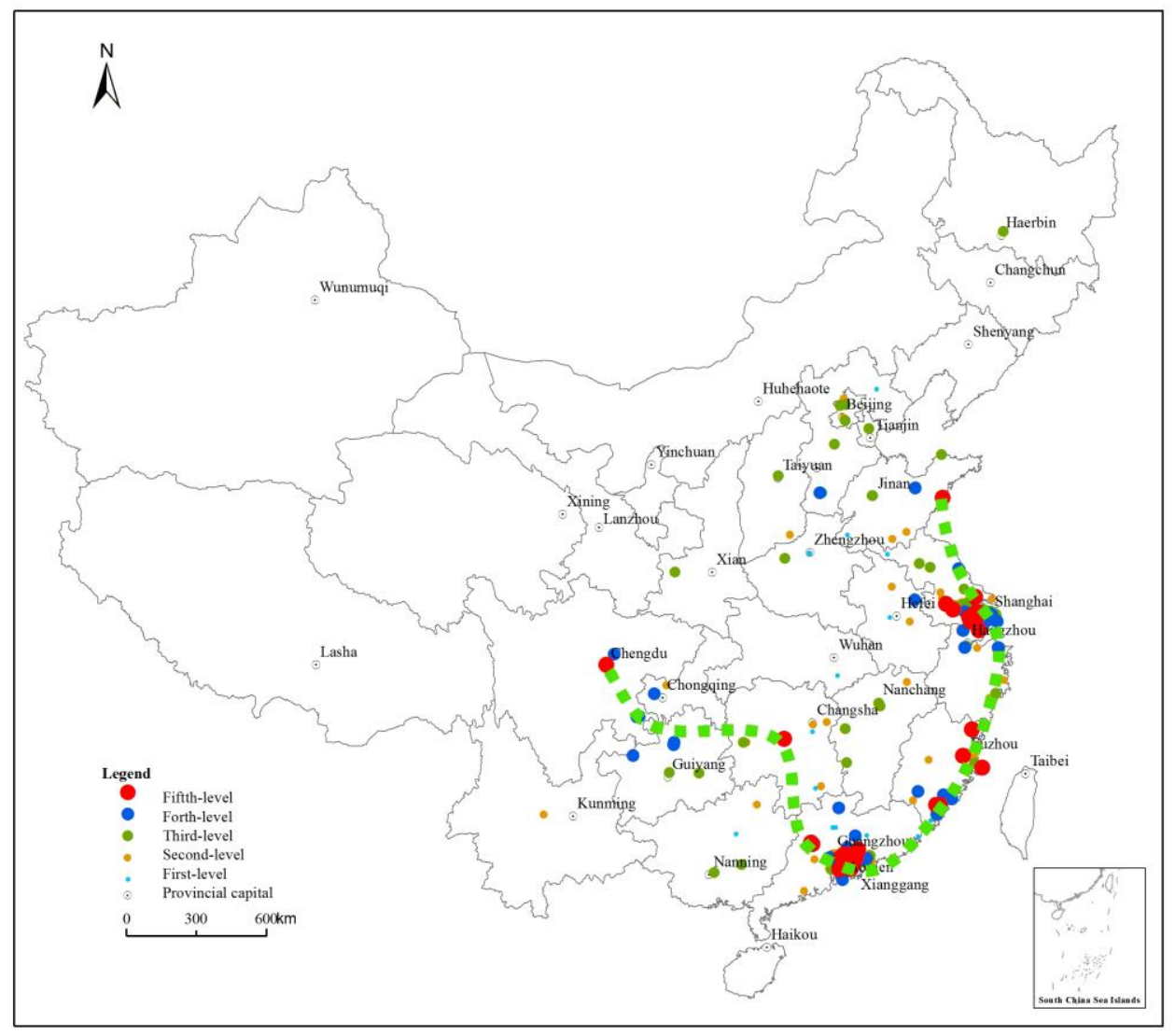

Figure 6. Distribution map of diffusion index grade of rural Taiwanese enterprises. 
Regionally speaking, rural Taiwanese enterprises with a high spatial diffusion index grade are mainly distributed in Dongguan, Shenzhen, Huizhou, Zhongshan, and Qingyuan in the Pearl River Delta area; in Fuzhou, Zhangzhou, and the Pingtan Comprehensive Experimental Zone in Fujian; in Suzhou, Nantong, Changzhou, and Zhenjiang in Jiangsu; and Jiaxing in Zhejiang of the Yangtze River Delta area. Furthermore, some of the enterprises are scattered in Qingdao of Shandong, Chengdu of Sichuan, and Loudi of Hunan.

\subsubsection{Process of Spatial Diffusion}

\section{(1) Regional Process}

The comprehensive spatial diffusion index of rural Taiwanese enterprises displays the trend of a fast increase at first, and decreases later, and the average diffusion index maintains a steady fluctuation for five years, as shown in Figure 7. The comprehensive diffusion index peaks around 2002, enters the sub-peak period (2003-2010) later, and starts to decline in 2011. The enterprises with a strong diffusion index are distributed in Guangdong, Jiangsu, Fujian, Zhejiang, and Shandong in the coastal area, and in Hunan and Sichuan in the hinterland, and form two high-index core clusters in Guangdong and Jiangsu.

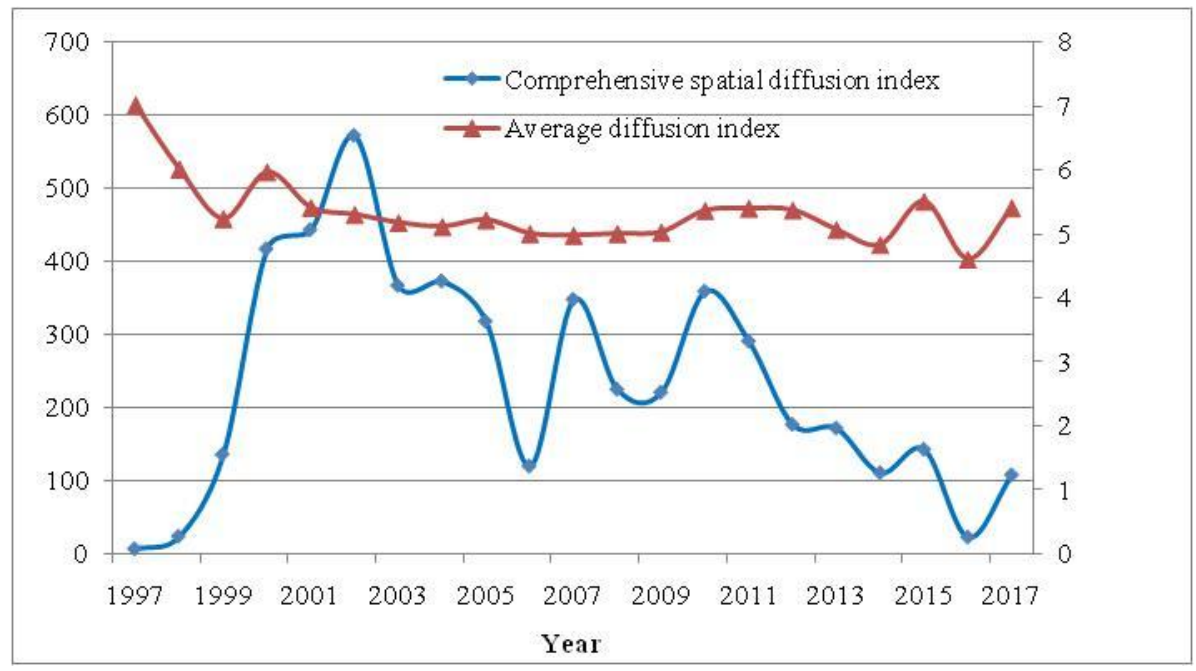

Figure 7. Diffusion index curve of rural Taiwanese enterprises.

\section{(2) Industrial Process}

The spatial diffusion index of the industries of rural the Taiwanese enterprises shows the feature of low-level development for the primary industry, with a fast increase at first and a decrease for the secondary industry later, with a decrease at first and a later increase for the tertiary industry, as shown in Figure 8. The diffusion index of the secondary industry reaches its peak around 2002 and starts to decline afterwards. The index of the tertiary industry peaks in 2010 and enters the stage of steady diffusion afterwards. The majority of rural Taiwanese enterprises are engaged in manufacturing and production, and their spatial diffusion index is close to the general status of growth of the enterprises.

As for the regional industry, the spatial diffusion index of rural Taiwanese enterprises is polarized. Guangdong outshines the others and the diffusion index of its three industries is far ahead of Jiangsu, which is in second place. Shanghai, Fujian, and Zhejiang are in third place and the other provinces and cities are in fourth. The diffusion index of the secondary industry peaks in 2002 and starts to decline afterwards. The index of the tertiary industry peaks around 2010 and enters the stage of steady diffusion afterwards. 


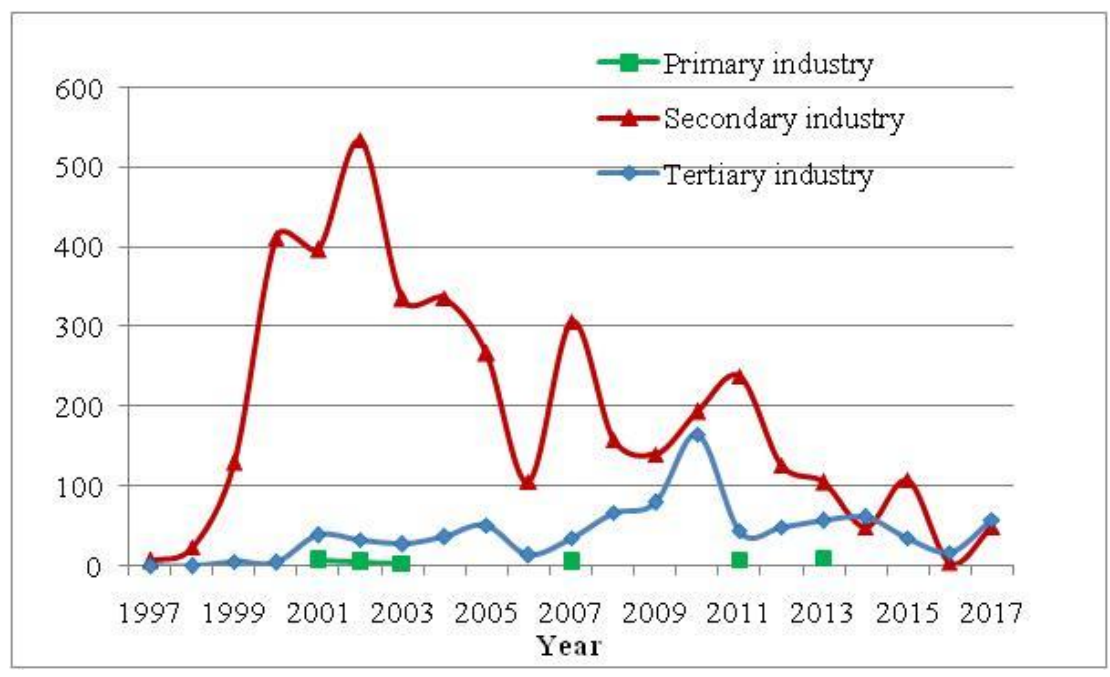

Figure 8. Industrial graph of diffusion index of rural Taiwanese enterprises.

\section{(3) Spatial Diffusion Model}

A spatial diffusion model is used to simulate the spatial diffusion of rural Taiwanese enterprises in 1997-2027, as indicated in Figure 9. As the number of the enterprises was small in 1997-1999, in order to avoid abnormal model fitting data, the average value in 1997-1999 was taken as the initial value and the initial year of the simulated value was 1999. MATLAB is adopted for the least squares parameter estimation over the spatial diffusion model, and the following model parameters are acquired:

$$
\begin{aligned}
& \alpha=0.042 \\
& b=0.208 \times 10^{-3} \\
& \bar{N}=999
\end{aligned}
$$

The coefficient of determination of the mixed model fitting curve, $R^{2}=0.990$, is close to 1 , indicating an admirable goodness of fit of the model.

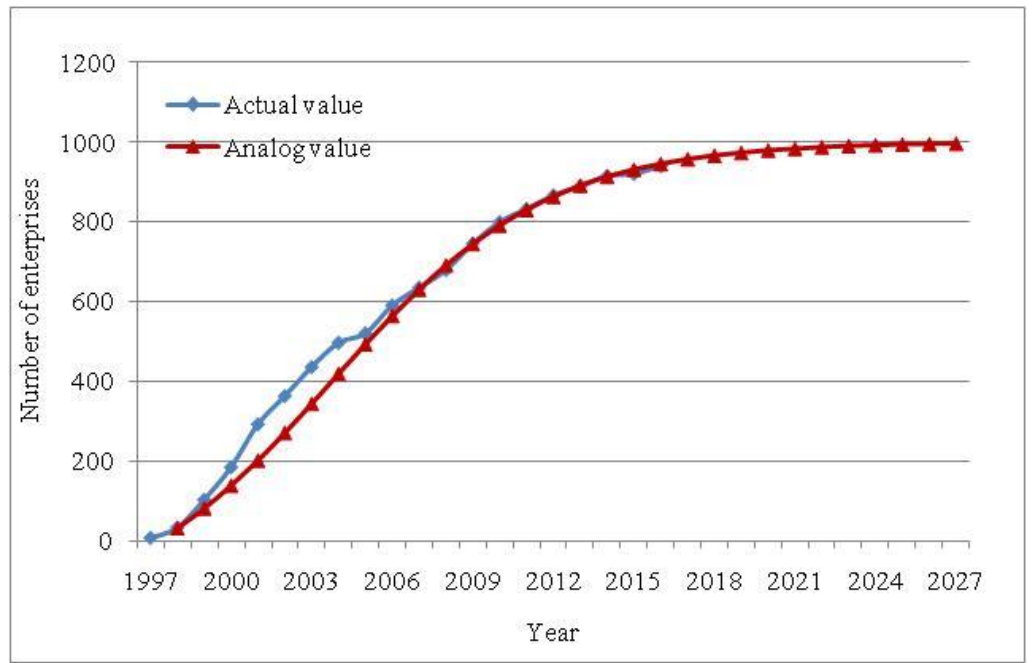

Figure 9. Simulation of the spatial diffusion of rural Taiwanese enterprises in 1997-2027.

In 1997-2017, the cumulative quantity of rural Taiwanese enterprises shows an S-shaped growth trend. The model is used to predict the spatial diffusion of rural Taiwanese enterprises in 2018-2027, and the number of enterprises is predicted to be 956 in 2018. In the next decade, based on the intensity of the current mixed influencing factors, the number will grow by less than 10 annually, and is 
predicted to approach 999 by 2027, according to the asymptote of the current parameter estimation curve. As the mainland population dividend decreases, the appeal to rural Taiwanese enterprises will be further reduced.

(4) Prediction for Spatial Diffusion

Based on the spatial diffusion model, the geostatistical analysis method [43] is used to predict the future spatial diffusion process of rural Taiwanese enterprises, as seen in Figure 10. Besides the existing high-index core clusters in the Yangtze River Delta and Pearl River Delta area, new high-index areas emerge as follows: (1) Sichuan-Chongqing-Guizhou, (2) Fujian-Zhejiang-Jiangxi, and (3) Jiangsu-Shandong-Beijing. A low-index area in Henan-Hubei-Hunan is found.

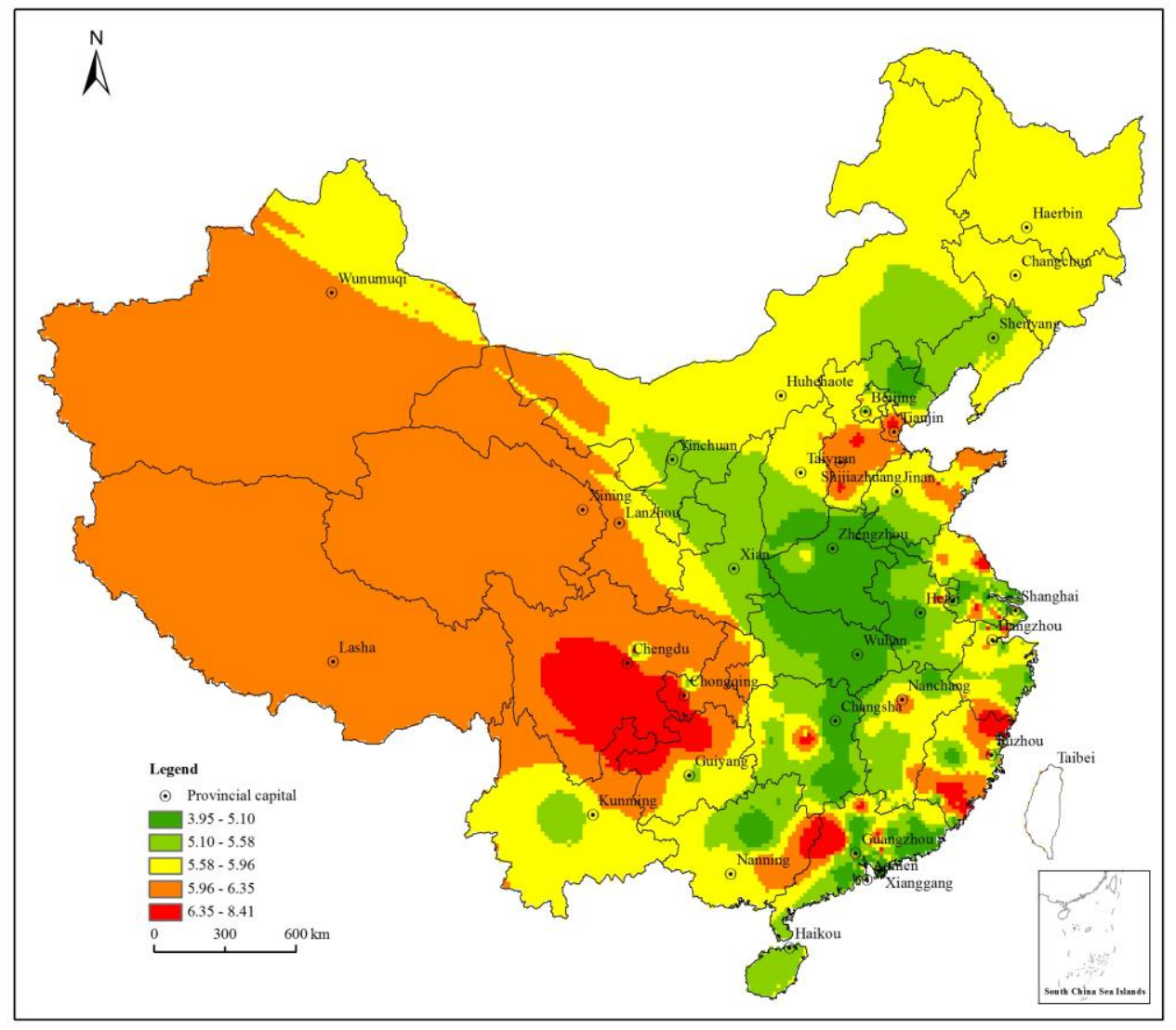

Figure 10. Spatial diffusion simulation of rural Taiwanese enterprises.

\section{Conclusion and Discussion}

Industrial vitalization is the foundation and key to rural vitalization. Taiwanese compatriots have accumulated rich experience in rural industrial vitalization. They also invest in mainland towns and villages so as to facilitate rural vitalization. The study collects the basic data on 941 Taiwanese enterprises that have been investing in mainland towns and villages for the past 30 years, and adopts a GIS spatial analysis method and cultural diffusion model to analyze the spatial pattern and spatial evolvement of rural Taiwanese enterprises. The following conclusions are drawn.

(1) In terms of temporal and spatial evolvement, the growth of rural Taiwanese enterprises is closely related to the domestic policies and international economic situation. They experienced explosive growth at the beginning of the 21st century, but slowed down slightly later. The spatial distribution of the enterprises shows the dual-core pattern around the Yangtze River Delta and Pearl River Delta, which differs from the "axe-shaped" general spatial distribution in the four core areas, Yangtze River Delta, Pearl River Delta, Beijing-Tianjin-Hebei, and Chengdu-Chongqing, of the Taiwanese enterprises in mainland China. The latter indicates that the Taiwanese enterprises in 
mainland China are predominated by city diffusion in Beijing-Tianjin-Hebei and Chengdu-Chongqing. The institutional dividend at the early stage shaped the agglomeration core foundation of Dongguan and Kunshan, and the combined effect was further enhanced and diffused at the stage of explosive growth, forming the "core- periphery" spatial structure. As the growth of rural the Taiwanese enterprises slowed down, the combined effect slightly weakened and the enterprises started to be diffused towards other Eastern, Central, and Western regions.

(2) Rural Taiwanese enterprises are mostly engaged in secondary industry, small in size, and highly independent. Generally speaking, their investment is limited by size and mainly goes to manufacturing and other labor-intensive and technology-intensive industries with low value added. Spatially speaking, they are mainly distributed in secondary cities in economically developed areas, so as to reduce cost and maximize profit. Regarding the methods of investment, sole proprietorship enterprises are dominant, with the exception of Fujian, which is home to more joint ventures. This reflects the low degree of cultural integration and exchange of Taiwanese enterprises in investment destinations.

(3) In terms of the general spatial diffusion process, the high-grade spatial diffusion index of rural Taiwanese enterprises displays the V-shaped spatial feature in Guangdong-FujianZhejiang-Jiangsu-Shandong and Guangdong-Guizhou-Sichuan. The comprehensive index shows the feature increase at first and decrease later, while the average spatial index remains around five. Regarding the industrial features, the diffusion index is featured by the low-level development of the primary industry, the increase at first and decrease later of the secondary industry, and the decrease at first and increase later of the tertiary industry.

(4) The diffusion model fitting with mixed influencing factors shows that the cumulative number of rural Taiwanese enterprises displays an S-shaped growth trend and is predicted to slow down in the next ten years, approaching 1000 by 2027. As forecast with the geo-statistical analysis method, the diffusion trend is noticeable in the Pearl River Delta, but is weak in the Yangtze River Delta, and new high-diffusion-index core areas are taking shape in the Sichuan-Chongqing area and Fujian-Zhejiang area.

The research also has important policy implications for China and other developing countries.

Firstly, the local state is powerful and its decision is crucial for attracting investment so as to promote rural industry. With the rapid economic development and the accelerated pace of urbanization, the Chinese government calls on all its policymakers at all levels to intensify action so as to promote rural development. The local state continues to be indispensable in rural industrial vitalization. In particular, officials favor policies that support direct investment and accelerate the capital, technology, and human capital exchange. The role of government policy in Taiwanese rural enterprises' location decisions, although still important, is shrinking as the significance of agglomeration increases.

Secondly, weak linkages with local economies, in a way, become barriers to cooperative development. A large percentage of Taiwanese rural enterprises are wholly-owned enterprises, and few local people have little control over the making of key decisions, although they have a higher level of insight into the local culture and local market. There is no incentive for Taiwanese rural enterprises to embed with local economies in research, technology, and strategy, which is consistent with findings based on other regions of China [44,45]. Taiwanese enterprises tend to adopt the strategy of group investment and geographical clustering, due to a similar cultural background, existing business relations, and the common political risks they face [46]. This clustering is also based on the production, credit, and social relations that were established among these firms in Taiwan, before they relocated to mainland China [47]. In order to reduce information barriers, both must find effective ways to collaborate.

Thirdly, China's rural area right now desperately needs a new engine of growth, and institution innovation seems like the obvious way to go. We are aware of the importance of the local state in the early stage, however, the land policy, market-access policy, and tax incentive method provide less of a boost to foreign investment after the initial growth stage. To reduce the dependence of 
foreign investment, the local state should better promote endogenous innovation capacities and the development of business services and private enterprises. "Creative platforms" are required in order to create incentives for research and development, attract domestic and foreign funding, and encourage cooperation and innovation. Rural area will be better off if more attention is paid to institution innovation.

In the study, space remains for improvement in the future. Firstly, the source of data still needs to be diversified, and data on the non-listed (OTC) Taiwanese enterprises setting up business in the mainland countryside can be added. Secondly, the engagement of Taiwanese compatriots in rural industrial vitalization in mainland China can also be realized through non-regular employment approaches such as technical consultation and service. The related information is not registered with the Taiwanese Compatriot Association and needs be acquired through interviews.

Author Contributions: M.L. designed and implemented the data analysis methods and wrote the manuscript. J.L. and K.W. supervised the data analysis, participated in writing, and revised the manuscript. C.L., and A.Z. assisted with the data analysis and manuscript preparation.

Funding: This research was funded by a project of the China Postdoctoral Science Foundation (grant no. 2017M610976), the National Natural Science Foundation of China (grant no. 41871146 and no. 4187208), and the Social Science Foundation of China (grant no. 18BJL126).

Acknowledgments: The authors appreciate the technical support of Yuewen Huang, Xiaozhen Wang, Suqiong Wei; and the valuable comments of the reviewers.

Conflicts of Interest: The authors declare no conflict of interest.

\section{Appendix A}

In this study, China is separated into four regions: the Eastern region, which includes 10 provinces and direct-controlled cities, namely, Beijing, Tianjin, Hebei, Shanghai, Jiangsu, Zhejiang, Fujian, Shandong, Guangdong, and Hainan; the Central region, which includes 6 provinces, namely, Shanxi, Anhui, Jiangxi, Henan, Hubei, and Hunan; the Western region, which includes 12 provinces, a direct-controlled city, and autonomous regions, namely, Inner Mongolia and Guangxi, and Chongqing, Sichuan, Guizhou, Yunnan, Tibet, Shaanxi, Gansu, Qinghai, Ningxia, and Xinjiang; and the Northeast region, which includes 3 provinces, namely, Liaoning, Jilin, and Heilongjiang.

\section{References}

1. Liu, Y.S.; Li, Y.H. Revitalize the world's countryside. Nature 2017, 548, 275-277. [CrossRef] [PubMed]

2. Korompai, A.; Szabó, M.; Nováky, E. Supporting the absorbent national rural development planning by scenarios. Eur. Countrys. 2017, 9, 416-434. [CrossRef]

3. Osterud, G. Farm crisis and rural revitalization in South-Central New York during the early twentieth century. Agric. Hist. 2010, 84, 141-165. [CrossRef] [PubMed]

4. Knight, J. Wolves in Japan? An examination of the reintroduction proposal. Jpn. Forum 1998, 10, 47-65. [CrossRef]

5. Pickles, J. Industrial restructuring, peripheral industrialization, and rural development in South Africa. Antipode 1991, 23, 68-91. [CrossRef]

6. Marsden, T.; Sonnino, R. Rural development and the regional state: Denying multifunctional agriculture in the UK. J. Rural Stud. 2008, 24, 422-431. [CrossRef]

7. Gürel, B. The role of collective mobilization in the divergent performance of the rural economies of China and India (1950-2005). J. Peasant Stud. 2018, 45, 1-26. [CrossRef]

8. Mahajan, V.; Peterson, R.A. Models for Innovation Diffusion; Sage Publications: Beverly Hills, CA, USA, 1985; pp. 1-10.

9. Knight, J. Rural Revitalization in Japan: Spirit of the Village and Taste of the Country. Asian Surv. 1994, 34, 634-646. [CrossRef]

10. Yiu, E. Noto peninsula after GIAHS designation: Conservation and revitalization efforts of Noto's Satoyama and Satoumi. J. Resour. Ecol. 2014, 5, 364-369. [CrossRef] 
11. Liu, Y.; Yu, L.; Chen, Y.; Long, H. The process and driving forces of rural hollowing in China under rapid urbanization. J. Geogr. Sci. 2010, 20, 876-888. [CrossRef]

12. Tu, S.S.; Long, H. Rural restructuring in China: Theory, approaches and research prospect. J. Geogr. Sci. 2017, 27, 1169-1184. [CrossRef]

13. Albert, P.; Bruce, J. Rural development and dynamic externalities in Taiwan's structural transformation. Econ. Dev. Cult. Chang. 2000, 44, 180-208. [CrossRef]

14. Chen, A.; Scott, S. Rural development strategies and government roles in the development of farmers' cooperatives in China. J. Agric. Food Syst. Community Dev. 2014, 4, 35-55. [CrossRef]

15. Ho, S.P.S. Economic development and rural industry in South Korea and Taiwan. World Dev. 1982, 10, 973-990. [CrossRef]

16. Chen, I.T.; Weicht, K.K. Tourism Development and Rural Tourism in Taiwan: A Literature Review. In Tourism and Opportunities for Economic Development in Asia; IGI Global: Hershey, PA, USA, 2017; pp. $203-223$. [CrossRef]

17. Cheng, E.S.K. Return migrants, mini-tours and rural regeneration: A study of local food movement in Taiwan. Asia Pac. Viewp. 2016, 57, 338-350. [CrossRef]

18. Fang, G.C.; Wu, Y.S.; Chang, C.N.; Fu, P.C.; Chang, K.F.; Yang, D.G. The characteristic study of TSP, PM2.5 similar to 10 and PM2.5 in the rural site of central Taiwan. Sci. Total Environ. 1999, 232, 177-184. [CrossRef]

19. Chiang, Y.C.; Tsai, F.F.; Chang, H.P.; Chen, C.F.; Huang, Y.C. Adaptive society in a changing environment: Insight into the social resilience of a rural region of Taiwan. Land Use Policy 2014, 36, 510-521. [CrossRef]

20. Wang, B.C.; Chou, F.Y.; Lee, Y.J. Awareness of Residents Regarding the Construction of a Sustainable Urban Community: A Case Study of Action Research in Taiwan. Syst. Prac. Action Res. 2010, 23, 157-172. [CrossRef]

21. Yang, C.; Liao, H. Industrial agglomeration of Hong Kong and Taiwanese manufacturing investment in China: A town-level analysis in Dongguan. Ann. Reg. Sci. 2010, 45, 487-517. [CrossRef]

22. Liao, F.H.F. Industrial agglomeration of Taiwanese electronics firms in Dongguan, China: A town-level analysis. Asian Geogr. 2009, 26, 1-21. [CrossRef]

23. Tsai, P.H.; Liu, C.W. Local economy growing at a steady pace: The case of the peasant farming project by the Taiwan rural front. China J. Soc. Work 2012, 5, 25-33. [CrossRef]

24. Fan, S.S.; Qiu, S.R.; Lin, J.B.; Su, B.C.; Yang, M.; Huang, B.W. Exploration on tourists' perception and willingness to pay for the ecological landscape quality of leisure farm: A case study of Fuyou Leisure Farm in Fujian Province. China Popul. Resour. Environ. 2016, 26, 167-176. [CrossRef]

25. Fan, S.; Zhang, L.; Zhang, X. Reforms, Investment, and Poverty in Rural China. Econ. Dev. Cult. Chang. 2004, 52, 395-421. [CrossRef]

26. Bell, M.M. The fruit of difference: The rural-urban continuum as a system of identity. Rural Soc. 1992, 57, 65-82. [CrossRef]

27. Long, H.L.; Liu, Y.S. Rural restructuring in China. J. Rural Stud. 2016, 478, 387-391. [CrossRef]

28. Smith, G. The hollow state: Rural governance in China. China Quart. 2010, 203, 601-618. [CrossRef]

29. Li, L.F. Mass movements and rural governance in communist China: 1945-1976. J. Mod. Chin. Hist. 2013, 7, 156-180. [CrossRef]

30. Long, H.; Jian, Z.; Pykett, J.; Li, Y. Analysis of rural transformation development in China since the turn of the new millennium. Appl. Geogr. 2011, 31, 1094-1105. [CrossRef]

31. Newland, S.A. Minzi Su, China's Rural Development Policy: Exploring the "New Socialist Countryside". J. Chin. Polit. Sci. 2011, 16, 117-118. [CrossRef]

32. Tian, L.; Yao, Z. From state-dominant to bottom-up redevelopment: Can institutional change facilitate urban and rural redevelopment in China. Cities 2018, 76, 72-83. [CrossRef]

33. Li, Y.H.; Hans, W.; Zheng, X.Y.; Liu, Y.S. Bottom-up initiatives and revival in the face of rural decline: Case studies from China and Sweden. J. Rural Stud. 2016, 47, 506-513. [CrossRef]

34. Leeuwis, C. Reconceptualizing Participation for Sustainable Rural Development: Towards a Negotiation Approach. Dev. Chang. 2010, 31, 931-959. [CrossRef]

35. Long, H.L.; Liu, Y.S.; Li, X.B. Building new countryside in China: A geographical perspective. Land Use Policy 2010, 27, 457-470. [CrossRef]

36. Walters, B.B.; Cadelina, A.; Cardano, A.; Visitacion, E. Community history and rural development: Why some farmers participate more readily than others. Agric. Syst. 1999, 59, 193-214. [CrossRef] 
37. Solana-Solana, M. Rural gentrification in Catalonia, Spain: A case study of migration, social change and conflicts in the Empordanet area. Geoforum 2010, 41, 508-517. [CrossRef]

38. Stefan, B.; Falck, O. Culture, spatial diffusion of ideas and their long-lasting imprints-Evidence from Froebel's kindergarten movement. J. Econ. Geogr. 2014, 15, 601-630. [CrossRef]

39. Dong, X.Y.; Putterman, L. China's rural industry and monopsony: An exploration. Pac. Econ. Rev. 2010, 1, 59-78. [CrossRef]

40. Pierotti, R.S. Increasing rejection of intimate partner violence: Evidence of global cultural diffusion. Am. Soc. Rev. 2013, 78, 240-265. [CrossRef]

41. Zhang, K.H.L. Why does so much FDI from Hong Kong and Taiwan go to Mainland China? China Econ. Rev. 2005, 16, 293-307. [CrossRef]

42. Atsuyuki, O.; Satoh, T.; Sugihara, K. A kernel density estimation method for networks, its computational method and a GIS-based tool. Int. J. Geogr. Inf. Sci. 2009, 23, 7-32. [CrossRef]

43. Lin, J.H.; Zhang, A.; Chen, W.H.; Lin, M.S. Estimates of daily PM2.5 exposure in Beijing using Spatio-Temporal Kriging Model. Sustainability 2018, 10, 2772. [CrossRef]

44. Wei, Y.H.D.; Li, L.; Ning, Y.M. Corporate networks, value chains, and spatial organization: A study of the computer industry in China. Urban Geogr. 2010, 31, 1118-1140. [CrossRef]

45. Zhou, Y.; Wei, Y.H.D. Globalization, innovation, and regional development in China. Environ. Plan. A 2011, 43, 781-785. [CrossRef]

46. Wei, Y.H.D. Network Linkages and Local Embeddedness of Foreign Ventures in China: The Case of Suzhou Municipality. Reg. Stud. 2015, 49, 287-299. [CrossRef]

47. Yang, C. Divergent hybrid capitalisms in China: Hong Kong and Taiwanese electronics clusters in Dongguan. Econ. Geogr. 2007, 83, 395-420. [CrossRef]

(C) 2018 by the authors. Licensee MDPI, Basel, Switzerland. This article is an open access article distributed under the terms and conditions of the Creative Commons Attribution (CC BY) license (http://creativecommons.org/licenses/by/4.0/). 